\title{
Multiple Viral Infection Detected from Influenza-Like Illness Cases in Indonesia
}

\author{
Kindi Adam, Krisna Nur Andriana Pangesti, and Vivi Setiawaty \\ Research and Development Center for Biomedical and Basic Health Technology, Jakarta, Indonesia \\ Correspondence should be addressed to Vivi Setiawaty; vivisetiawaty@hotmail.com
}

Received 27 July 2016; Revised 22 November 2016; Accepted 13 December 2016; Published 23 January 2017

Academic Editor: Sumit Sharma

Copyright (C) 2017 Kindi Adam et al. This is an open access article distributed under the Creative Commons Attribution License, which permits unrestricted use, distribution, and reproduction in any medium, provided the original work is properly cited.

Influenza is one of the common etiologies of the upper respiratory tract infection (URTI). However, influenza virus only contributes about 20 percent of influenza-like illness patients. The aim of the study is to investigate the other viral etiologies from ILI cases in Indonesia. Of the 334 samples, 266 samples (78\%) were positive at least for one virus, including 107 (42\%) cases of multiple infections. Influenza virus is the most detected virus. The most frequent combination of viruses identified was adenovirus and human rhinovirus. This recent study demonstrated high detection rate of several respiratory viruses from ILI cases in Indonesia. Further studies to determine the relationship between viruses and clinical features are needed to improve respiratory disease control program.

\section{Introduction}

Lower respiratory tract infection (LRTI) remains one of the major causes of mortality and morbidity in children under five years globally [1]. Viruses have already been recognized as important etiologies of respiratory infections with influenza virus which is considered as the main contributor. The epidemiology and public health impact of influenza infections are relatively well described as many studies and surveillance have been conducted in part of pandemic preparedness [2-5]. Most of the countries in the world, including Indonesia, have developed influenza surveillance, influenzalike illness (ILI) surveillance, and severe acute respiratory illness (SARI), which form the network under WHO through Global Influenza Surveillance and Response Systems (GISRS) [4-8]. This network improves influenza disease control by providing support on influenza vaccine recommendation, laboratory diagnostic tools, antiviral, and public health risk assessment. As influenza virus contributed only less than 30 percent of viral respiratory infections, there is an urge to investigate the contribution of other respiratory viruses for improving respiratory disease control program [6].

Recent advancement of molecular technology supports the investigation and characterization of several respiratory viruses. The molecular technology improves the capability to study respiratory viruses, which are previously identified: rhinovirus, adenovirus, respiratory syncytial viruses, parainfluenza virus, and also the new emerging viruses/strain viruses: MERS coronavirus, human metapneumovirus, and human rhinovirus strain C. Multiple detection platforms, which recently have been developed, allows relatively inexpensive and timely detection of several viruses [9-11]. The detection of multiple respiratory viruses will accommodate the efforts to determine the epidemiology of noninfluenza respiratory viruses in the community, which will further help the respiratory disease control program including the use of antimicrobial agents [12].

Previous results of the investigation on acute respiratory infection patients in several countries showed the difference in the prevalence of respiratory viruses among studies [3, 13-15]. Study design including the case definition, study population, time of the study, and diagnostic tools being used have been considered as factors that influenced the variation [16]. Each virus has different seasonality circulation and an age-related prevalence that can lead to a specific pattern of virus cocirculation in many studies [17-19]. Moreover, the occurrence of virus coinfection in which two or more viruses are detected in a single patient has been described in recent studies using multiple pathogen detection platforms [20-22]. 


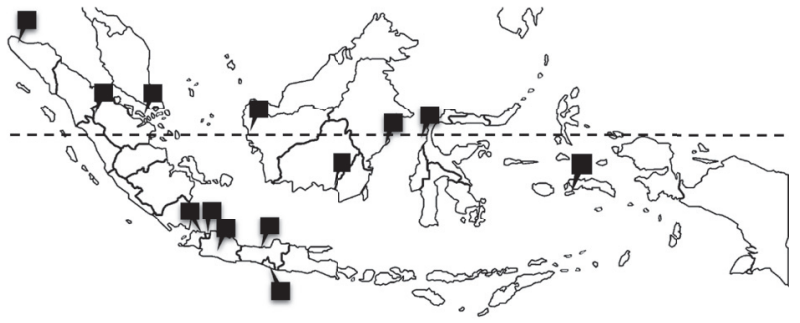

FIGURE 1: Location of ILI sentinels in 13 provinces in Indonesia.

There are limited studies on viral pathogens of respiratory tract infection in low-middle income countries including Indonesia. Previous studies have been conducted mostly focused on specific viral pathogens, especially influenza [6, $23,24]$. The prevalence of noninfluenza respiratory infections is relatively unknown. Therefore, this study has an objective to investigate the prevalence of viral etiologies from ILI cases in Indonesia.

\section{Method}

2.1. Study Design and Samples. Influenza-like illness (ILI) surveillance was conducted in thirteen sentinels' public health center across 13 Indonesia provinces in 2012 in Figure 1. The WHO case definitions were used to determine the ILI cases: fever $\geq 38^{\circ} \mathrm{C}$ and a cough or a sore throat [25]. Demographic and clinical data were obtained from questionnaires that are filled out by trained staff. Throat swab and nasal swabs from 1,692 patients were collected in viral transport medium (VTM), which were then sent to the Virology Laboratory, National Institute of Health Research and Development (NIHRD) in Jakarta. The VTM consists of bovine serum albumin, penicillin, streptomycin, and amphotericin $\mathrm{B}$, according to $\mathrm{WHO}$ surveillance manual [6]. Only specimens were received by the laboratory within three days after the collection was processed for molecular examinations. Specimens were stored in a -80 freezer prior to the laboratory tests. For this multiplex study, a total of three hundred thirty-four specimens were randomly selected.

2.2. Nucleic Acid Extraction and Multiplex PCR. Total viral nucleic acid was extracted from $190 \mu$ l of viral transport medium using RiboSpin v_RD GeneAll extraction Kit from Seegene (Seegene Inc., Seoul, South Korea). A $10 \mu$ internal control which is inserted in the package was added to each of the $190 \mu \mathrm{l}$ samples for internal amplification control to check the PCR process. $40 \mu$ l elution buffer was added according to the manufacturer instructions. Seeplex ${ }^{\circledR}$ RV16 ACE Multiplex detection (Seegene Inc., Seoul, South Korea), a multiplex real time PCR platform, which is able to detect 16 viruses including human adenovirus (ADV), influenza $\mathrm{A}$ and $\mathrm{B}$ viruses (Flu $\mathrm{A}$, Flu B), human parainfluenza viruses 1/2/3/4 (PIV 1/2/3/4), human rhinoviruses A/B/C (RV $\mathrm{A} / \mathrm{B} / \mathrm{C}$ ), human respiratory syncytial viruses $\mathrm{A}$ and $\mathrm{B}$ (RSV A, RSV B), human bocaviruses 1/2/3/4 (BoV1/2/3/4), human coronaviruses 229E, NL63 and OC43 (CoV-229E, CoVNL63, and CoV-OC43), human metapneumovirus (hMPV), and human enterovirus (EV) was used. The protocol followed manufacturer's instruction as described before [26].

cDNA synthesis process was performed using cDNA synthesis premix (Seegene Inc., Seoul, South Korea) with $8 \mu \mathrm{l}$ of RNA, $2 \mu \mathrm{l}$ random hexamer primer, and $10 \mu \mathrm{lmix}$ of transcriptase, $\mathrm{MgCl}_{2}$, $\mathrm{dNTP}$, and buffer. The multiplex reaction was performed using Biorad CFX 96 Real Time Thermal Cycler. The reaction mixture was first denatured at $95^{\circ} \mathrm{C}$ for $15 \mathrm{~min}$, followed by 50 cycles of denaturation at $95^{\circ} \mathrm{C}$ for $30 \mathrm{~s}$, annealing at $60^{\circ} \mathrm{C}$ for $60 \mathrm{~s}$, extension at $72^{\circ} \mathrm{C}$ for $30 \mathrm{~s}$, and a final extension step at $55^{\circ} \mathrm{C}$ for $30 \mathrm{~s}$. The melting curve temperature from $55^{\circ} \mathrm{C}$ to $85^{\circ} \mathrm{C}\left(5 \mathrm{~s} / 0,5^{\circ} \mathrm{C}\right)$ was used to read the amplification. Any positive result was detected as a peak in electropherogram, compared to positive control.

2.3. Statistical Analysis. The descriptive statistics were used to analyse demographics, clinical, and laboratory data using Microsoft Excel (Microsoft Corporation, Washington, US). To compare between single and multiple infection, two paired tests were used.

2.4. Ethical Approval. This study has been approved by the Health Research Ethics Committee, National Institute of Health Research and Development, Ministry of Health, Indonesia.

\section{Results and Discussion}

This present study is the first study reporting respiratory viruses' detection in ILI patients in Indonesia. During 2012, 1692 patients that meet ILI case definition criteria were enrolled. From 334 cases randomly selected, 175 (52.3\%) were male and 159 (47.6\%) were female. The median age was nine years with a range from 1 month to 79 years. Most of the cases selected were patients with age $>5$ years old $(60.7 \%)$.

Two hundred and fifty-six (76.6\%) specimens contained one or more viruses. Single infection was detected in 138 $(41.32 \%)$ cases and multiple infections were identified in $105(31.4 \%)$ samples. The high detection rate of respiratory viruses from ILI cases in this study is similar to the previous studies in other countries including Cameroon (65.06\%), Nanjing China (50.6\%), and Cambodia (35.5\%) [3, 14, 15]. However, this result is higher compared to the previous results which focused on hospitalized patients in Indonesia: $27 \%$ and $8.2 \%[23,27]$. The difference of viral detection rate among outpatient ILI cases and inpatient is most likely due to the time of infection. Hospitalized patients who suffer from lower respiratory tract infection might experience viral infection first which is then followed by bacterial infection later.

Of these positive specimens, influenza virus is the most detected virus (36.1\%), followed by human rhinovirus and human adenovirus. Table 1 shows the distribution of respiratory viruses associated with ILI cases in 2012. The high prevalence of influenza virus detected from ILI cases in this recent study is concordant with several results from other countries $[3,15,28]$. Previous results in hospitalized suspected influenza patients in Indonesia demonstrated similar results as influenza is the most detected virus. 
TABLE 1: Viral etiology of ILI cases.

\begin{tabular}{|c|c|c|c|c|c|c|}
\hline \multirow{2}{*}{ Virus } & \multicolumn{2}{|c|}{ Total } & \multicolumn{2}{|c|}{ Single } & \multicolumn{2}{|c|}{ Multiple } \\
\hline & $N$ & (\%) & $N$ & $(\%)$ & $N$ & $(\%)$ \\
\hline \multicolumn{7}{|l|}{ Influenza } \\
\hline Influenza A & 63 & 18.75 & 27 & 42.86 & 36 & 57.14 \\
\hline Influenza B & 58 & 17.26 & 25 & 43.10 & 33 & 56.90 \\
\hline Human rhinovirus & 76 & 22.62 & 29 & 38.16 & 47 & 61.84 \\
\hline Human adenovirus & 67 & 19.94 & 12 & 17.91 & 55 & 82.09 \\
\hline \multicolumn{7}{|c|}{ Respiratory syncytial virus } \\
\hline RSV A & 53 & 15.77 & 19 & 35.85 & 34 & 64.15 \\
\hline RSV B & 4 & 1.19 & 1 & 25 & 3 & 75 \\
\hline Human enterovirus & 36 & 10.71 & 13 & 36.11 & 23 & 63.89 \\
\hline \multicolumn{7}{|l|}{ Parainfluenza virus } \\
\hline PIV 1 & 12 & 3.57 & 2 & 16.67 & 10 & 83.33 \\
\hline PIV 2 & 2 & 0.60 & 0 & 0 & 2 & 100 \\
\hline PIV 3 & 5 & 1.49 & 4 & 80 & 1 & 20 \\
\hline PIV 4 & 1 & 0.30 & 0 & 0 & 1 & 100 \\
\hline Human bocavirus & 15 & 4.46 & 2 & 13.33 & 13 & 86.67 \\
\hline \multicolumn{7}{|l|}{ Human coronavirus } \\
\hline Type NL63 & 6 & 1.79 & 2 & 33.33 & 4 & 66.67 \\
\hline Type OC43 & 4 & 1.19 & 1 & 25 & 3 & 75 \\
\hline Type $229 \mathrm{E}$ & 3 & 0.89 & 1 & 33.33 & 2 & 66.67 \\
\hline
\end{tabular}

The difference in the prevalence of viruses identified in the ILI specimens among studies has been recognized. Time of samples collection and the composition of age in the study population are assumed to influence the proportion of virus identified [3]. Previous results between studies in temperate countries showed the variation of viruses detected based on the seasons $[18,29]$. The seasonality of respiratory viruses in tropical region is relatively undefined clearly except for RSV and influenza seasonality which associated with rainy seasons [30]. Therefore, further investigation is needed to determine the seasonality of other respiratory viruses in the tropic region.

The prevalence of viruses is assumed to be associated with the age of patients. Regarding the age group in this study which is mostly more than 5 years old, the prevalence of RSV was low as RSV is mostly detected in children under one year old. The prevalence of adenovirus and RSV A infections increased with age. This finding is similar to other researches [20]. Influenza was the most prevalent viral infection underone-year-old group and above-five-year-old group. In the one-to-five-year-old group, adenovirus was the most prevalent. Figure 2 also shows the number of respiratory virus infections by each age group.

The frequency of multiple infections $(31,4 \%)$ in all ages was significantly higher than single infection $(45,2 \%)(Z=$ $5,069, P<0,0001,95 \%$ CI $0,2647-0,3636)$. This number is higher than the previous study in China $(10,8 \%)$. [3] The viral coinfection in children under five years old in this study is slightly higher than the older one (52.3\%). This result is the same as several other studies [18,20,22]. From the coinfection detected, the most frequent combination of viruses was ADV
TABLE 2: Contribution of respiratory viruses as single or coinfections.

\begin{tabular}{lcccccc}
\hline & ADV & Flu A & Flu B & HRV & RSV A & HEV \\
\hline ADV & $\mathbf{( 1 2 )}$ & & & & & \\
Flu A & 11 & $(\mathbf{2 7 )}$ & & & & \\
Flu B & 14 & 4 & $\mathbf{( 2 5 )}$ & & & \\
HRV & 20 & 17 & 11 & $\mathbf{( 2 9 )}$ & & \\
RSV A & 13 & 13 & 10 & 13 & $\mathbf{( 1 9 )}$ & \\
HEV & 1 & 8 & 4 & 6 & 5 & $\mathbf{( 1 3 )}$ \\
\hline
\end{tabular}

Note. Numbers in brackets indicate single infection.

and HRV. The frequency and combination of multiple viruses detected are presented in Table 2.

Indonesia has five major islands with Java Island as the main island where 5 of 13 sentinels located. The total number of influenza-like illness cases in the first quarter of the year was greater than the rest of the year, as shown in Table 3. Respiratory viruses were more frequently detected in the early months of the year in all regions in Indonesia. However, the virus detection rate in each month was not significantly different. The increased respiratory infections during this period may be related to the rainy season in Indonesia which usually starts from October to April, annually. The humidity and temperature are assumed to be major factors, as described before $[19,31]$. Respiratory viruses use aerosol as a mode of transmission. In the high humidity atmosphere as in tropical countries like Indonesia, the aerosol that contains respiratory viruses will survive longer. 
TABLE 3: Geographic distribution of positive viral infections from influenza-like illness patients, by month of specimen collection.

\begin{tabular}{lcccccccccc}
\hline Island & Jan & Feb & Mar & Apr & May & Jun & Jul & Aug & Sept & Total \\
\hline Sumatera & $12(14)$ & $3(6)$ & $8(8)$ & $9(10)$ & $0(2)$ & $1(2)$ & $2(2)$ & $1(1)$ & 0 & $\mathbf{4 5}$ \\
Java & $26(33)$ & $27(35)$ & $24(30)$ & $13(18)$ & $15(18)$ & $11(13)$ & $8(8)$ & $7(7)$ & $3(4)$ & $\mathbf{1 6 6}$ \\
Kalimantan & $5(6)$ & $17(17)$ & $8(9)$ & $13(14)$ & $10(15)$ & $4(7)$ & $7(9)$ & $0(1)$ & $3(6)$ & $\mathbf{8 4}$ \\
Sulawesi & $3(3)$ & $1(1)$ & $0(1)$ & $1(3)$ & $2(3)$ & $2(3)$ & $4(4)$ & $0(2)$ & $1(1)$ & $\mathbf{2 1}$ \\
East Indo & $4(4)$ & $2(2)$ & $1(3)$ & $1(1)$ & 0 & $1(2)$ & $0(2)$ & $1(2)$ & $2(2)$ & $\mathbf{1 8}$ \\
Total & & & & & & & & & $\mathbf{3 3 4}$ \\
\hline
\end{tabular}

Note. Numbers in brackets indicate ILI patients.

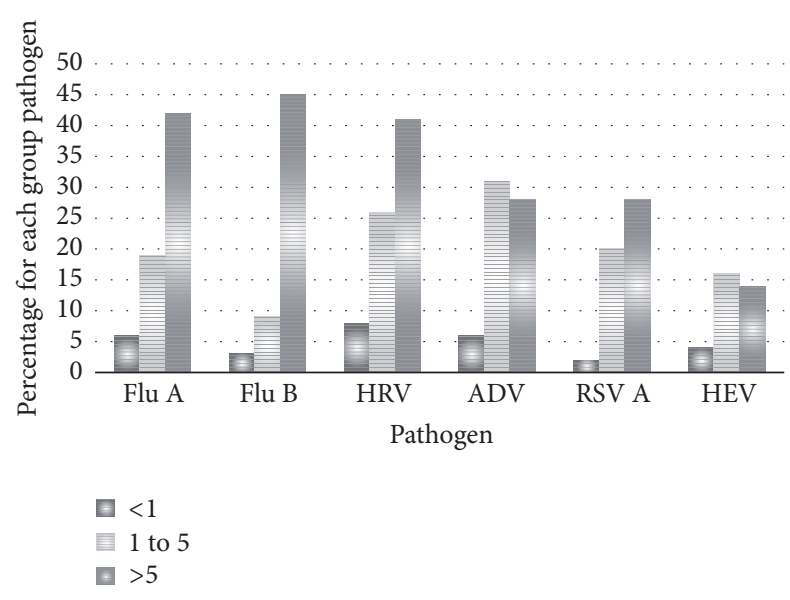

FIGURE 2: Virus detection by age group from influenza-like illness patients. A total of 27 patients $<1$ year old, 104 patients aged 1 to 5 years, and 203 patients aged $>5$ years were tested.

Our recent study has several limitations. First, fewer patients $<1$ year old were enrolled. Specimens from young children tend to be hard to collect. There may have been selection bias, as surveillance staff may have avoided collecting swabs from this age group. Second, we only sampled patients visiting public health centers. Our findings may be limited to patients at private clinics or those who do not seek healthcare. Third, our study did not analyse the relationship among viruses, coinfection, and clinical features (severity). Further studies are encouraged to determine the type of viruses and coinfections that contribute to disease severity.

\section{Conclusion}

This study demonstrates a variety of respiratory viruses in all ages of patients which come to ILI sentinel. High incidence of multiple infections in ILI cases in Indonesia was detected from January to April 2012. The ILI surveillance system has provided valuable data of the other respiratory viral pathogen and can be used to provide more information to the clinicians. More detailed information is useful in future studies to provide a complete picture of respiratory viruses disease burden.

\section{Competing Interests}

The authors declare that there is no conflict of interests regarding the publication of this paper.

\section{Acknowledgments}

This study was funded by Government Funding of National Institute of Health Research and Development, Ministry of Health, Indonesia. The authors are grateful for the technical support from INA-RESPOND, ILI sentinels, and Directorate of Acute Respiratory Infection and Directorate of Surveillance of Center for Disease Control and Prevention, Ministry of Health, Indonesia.

\section{References}

[1] L. Liu, S. Oza, D. Hogan et al., "Global, regional, and national causes of child mortality in 2000-2013, with projections to inform post-2015 priorities: an updated systematic analysis," The Lancet, vol. 385, no. 9966, pp. 430-440, 2015.

[2] Y. T. Nguyen, S. B. Graitcer, T. H. Nguyen et al., "National surveillance for influenza and influenza-like illness in Vietnam, 2006-2010," Vaccine, vol. 31, no. 40, pp. 4368-4374, 2013.

[3] X. Huo, Y. Qin, X. Qi et al., "Surveillance of 16 respiratory viruses in patients with influenza-like illness in Nanjing, China," Journal of Medical Virology, vol. 84, no. 12, pp. 1980-1984, 2012.

[4] J. J. M. Tamfum, E. Nkwembe, S. K. Bi Shamamba et al., "Sentinel surveillance for influenza-like illness, severe acute respiratory illness, and laboratory-confirmed influenza in kinshasa, democratic republic of Congo, 2009-2011," The Journal of Infectious Diseases, vol. 206, supplement 1, pp. S36-S40, 2012.

[5] E. Azziz-Baumgartner, A. S. M. Alamgir, M. Rahman et al., "Incidence of influenza-like illness and severe acute respiratory infection during three influenza seasons in Bangladesh, 20082010," Bulletin of the World Health Organization, vol. 90, no. 1, pp. 12-19, 2012.

[6] H. Kosasih, Roselinda, Nurhayati et al., "Surveillance of influenza in Indonesia, 2003-2007," Influenza and Other Respiratory Viruses, vol. 7, no. 3, pp. 312-320, 2013.

[7] H. Zhao, H. Green, A. Lackenby et al., "A new laboratorybased surveillance system (Respiratory DataMart System) for influenza and other respiratory viruses in England: results and experience from 2009 to 2012," Euro Surveillance, vol. 19, no. 3, 2014.

[8] W. K. Ampofo, E. Azziz-Baumgartner, U. Bashir et al., "Strengthening the influenza vaccine virus selection and development process: report of the 3rd WHO informal consultation for improving influenza vaccine virus selection held at WHO headquarters, Geneva, Switzerland, 1-3 April 2014," Vaccine, vol. 33, no. 36, pp. 4368-4382, 2015.

[9] A. M. Caliendo, "Multiplex PCR and emerging technologies for the detection of respiratory pathogens," Clinical Infectious Diseases, vol. 52, no. 4, pp. S326-S330, 2011. 
[10] P. Gautret, G. C. Gray, R. N. Charrel et al., "Emerging viral respiratory tract infections-environmental risk factors and transmission," The Lancet Infectious Diseases, vol. 14, no. 11, pp. 1113-1122, 2014.

[11] R. A. Borchardt and K. V. Rolston, "Respiratory tract infections: emerging viral pathogens," Journal of the American Academy of Physician Assistants, vol. 25, no. 10, pp. 19-20, 2012.

[12] R. Brittain-Long, J. Westin, S. Olofsson, M. Lindh, and L.M. Andersson, "Access to a polymerase chain reaction assay method targeting 13 respiratory viruses can reduce antibiotics: a randomised, controlled trial," BMC Medicine, vol. 9, article no. 44, 2011.

[13] S. D. Thiberville, L. Ninove, V. V. Hai et al., "The viral etiology of an influenza-like illness during the 2009 pandemic," Journal of Medical Virology, vol. 84, no. 7, pp. 1071-1079, 2012.

[14] C. Buecher, S. Mardy, W. Wang et al., "Use of a multiplex PCR/RT-PCR approach to assess the viral causes of influenzalike illnesses in Cambodia during three consecutive dry seasons," Journal of Medical Virology, vol. 82, no. 10, pp. 1762-1772, 2010.

[15] R. Njouom, E. L. Yekwa, P. Cappy, A. Vabret, P. Boisier, and D. Rousset, "Viral etiology of influenza-like illnesses in Cameroon, January-December 2009," Journal of Infectious Diseases, vol. 206, supplement 1, pp. S29-S35, 2012.

[16] E. T. Martin, M. P. Fairchok, Z. J. Stednick, J. Kuypers, and J. A. Englund, "Epidemiology of multiple respiratory viruses in childcare attendees," Journal of Infectious Diseases, vol. 207, no. 6, pp. 982-989, 2013.

[17] E. A. F. Simoes, "Environmental and demographic risk factors for respiratory syncytial virus lower respiratory tract disease," The Journal of Pediatrics, vol. 143, no. 5, supplement, pp. S118S126, 2003.

[18] B. Lina, M. Valette, S. Foray et al., "Surveillance of communityacquired viral infections due to respiratory viruses in RhoneAlpes (France) during winter 1994 to 1995," Journal of Clinical Microbiology, vol. 34, no. 12, pp. 3007-3011, 1996.

[19] A. S. Monto, "Occurrence of respiratory virus: time, place and person," The Pediatric Infectious Disease Journal, vol. 23, no. 1, pp. S58-S64, 2004.

[20] R. Brittain-Long, S. Nord, S. Olofsson, J. Westin, L.-M. Anderson, and M. Lindh, "Multiplex real-time PCR for detection of respiratory tract infections," Journal of Clinical Virology, vol. 41, no. 1, pp. 53-56, 2008.

[21] L. Bonzel, T. Tenenbaum, H. Schroten, O. Schildgen, S. Schweitzer-Krantz, and O. Adams, "Frequent detection of viral coinfection in children hospitalized with acute respiratory tract infection using a real-time polymerase chain reaction," The Pediatric Infectious Disease Journal, vol. 27, no. 7, pp. 589-594, 2008.

[22] T. J. Meerhoff, M. L. Houben, F. E. J. Coenjaerts et al., "Detection of multiple respiratory pathogens during primary respiratory infection: nasal swab versus nasopharyngeal aspirate using realtime polymerase chain reaction," European Journal of Clinical Microbiology and Infectious Diseases, vol. 29, no. 4, pp. 365-371, 2010.

[23] H. F. L. Wertheim, B. Nadjm, S. Thomas et al., "Viral and atypical bacterial aetiologies of infection in hospitalised patients admitted with clinical suspicion of influenza in Thailand, Vietnam and Indonesia," Influenza and Other Respiratory Viruses, vol. 9, no. 6, pp. 315-322, 2015.

[24] E. A. F. Simões, K. Mutyara, S. Soh, D. Agustian, M. L. Hibberd, and C. B. Kartasasmita, "The epidemiology of respiratory syn- cytial virus lower respiratory tract infections in children less than 5 years of age in indonesia," The Pediatric Infectious Disease Journal, vol. 30, no. 9, pp. 778-784, 2011.

[25] J. R. Ortiz, V. Sotomayor, O. C. Uez et al., "Strategy to enhance influenza surveillance worldwide," Emerging Infectious Diseases, vol. 15, no. 8, pp. 1271-1278, 2009.

[26] H.-K. Kim, S.-H. Oh, K. A. Yun, H. Sung, and M.-N. Kim, "Comparison of Anyplex II RV16 with the xTAG respiratory viral panel and Seeplex RV15 for detection of respiratory viruses," Journal of Clinical Microbiology, vol. 51, no. 4, pp. 11371141, 2013.

[27] A. Agustiningsih, R. Herman, R. Ramadhany, E. Pratiwi, K. D. Puspa, and V. Setiawaty, "Viral and bacterial infection among hospitalized-suspected influenza A/H5N1 patients in Indonesia, 2008-2009," Medical Journal of Indonesia, vol. 21, no. 2, pp. 77$82,2012$.

[28] A. Hombrouck, M. Sabbe, V. Van Casteren et al., "Viral aetiology of influenza-like illness in Belgium during the influenza A(H1N1)2009 pandemic," European Journal of Clinical Microbiology \& Infectious Diseases, vol. 31, no. 6, pp. 999-1007, 2012.

[29] L. Minodier, C. Arena, G. Heuze, M. Ruello, and J. P. Amoros, "Correction: epidemiology and viral etiology of the influenzalike illness in Corsica during the 2012-2013 winter: an analysis of several sentinel surveillance systems," PLOS ONE, vol. 9, no. 9, Article ID e107844, 2014.

[30] L. P. Shek and B.-W. Lee, "Epidemiology and seasonality of respiratory tract virus infections in the tropics," Paediatric Respiratory Reviews, vol. 4, no. 2, pp. 105-111, 2003.

[31] J.-B. Du Prel, W. Puppe, B. Gröndahl et al., "Are meteorological parameters associated with acute respiratory tract infections?" Clinical Infectious Diseases, vol. 49, no. 6, pp. 861-868, 2009. 

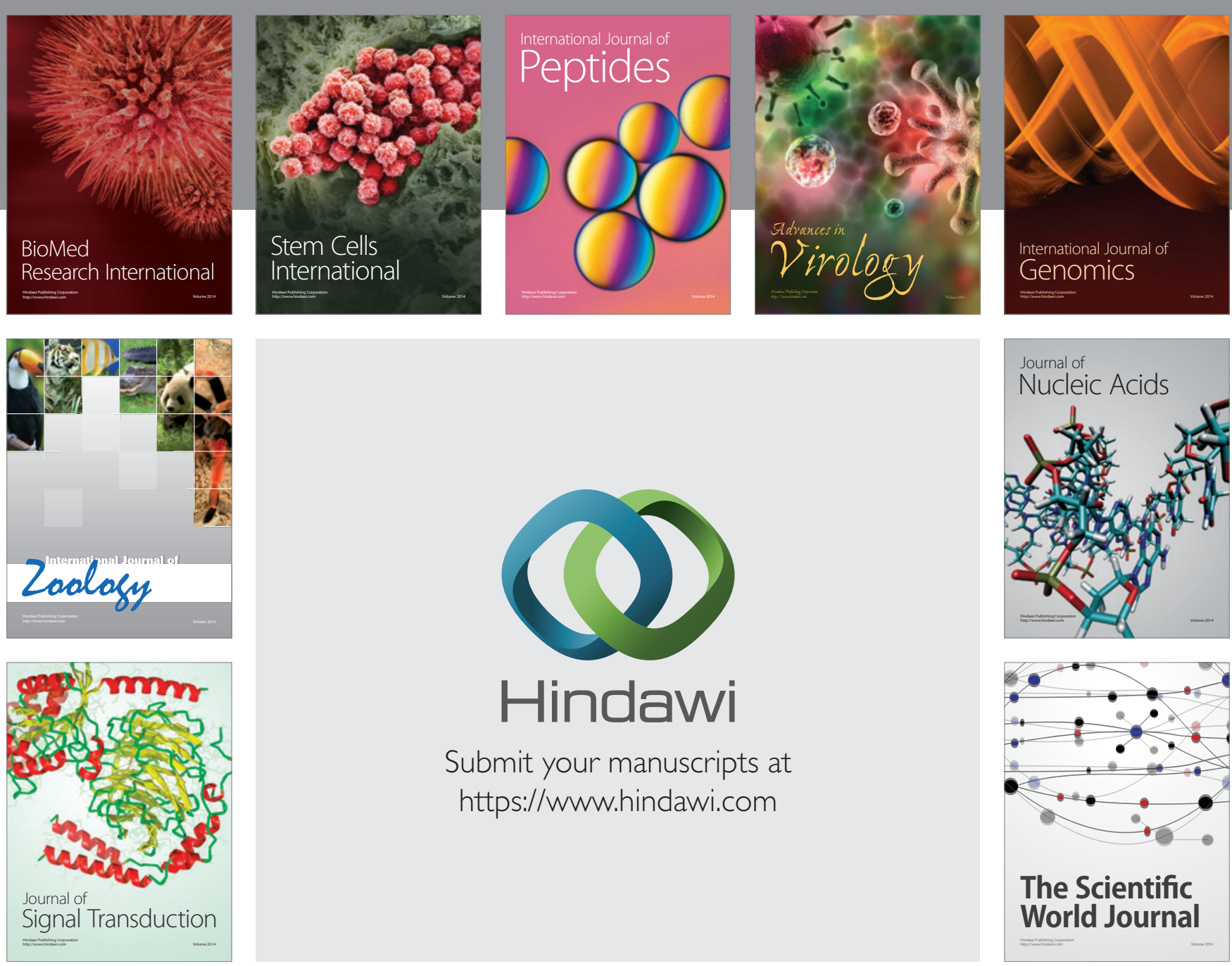

Submit your manuscripts at

https://www.hindawi.com
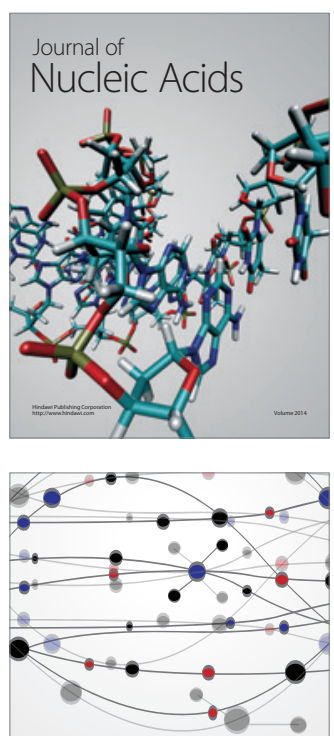

The Scientific World Journal
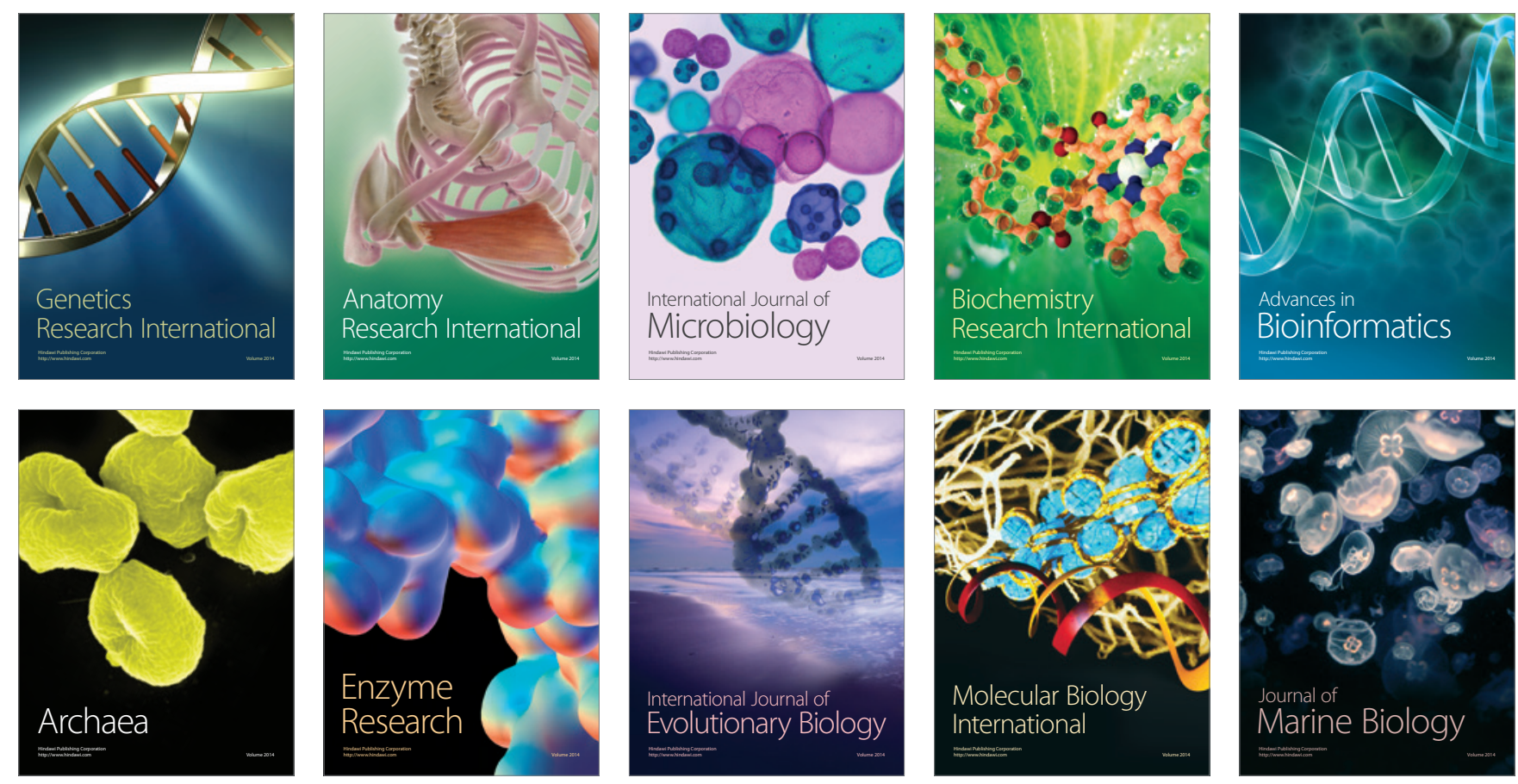